\title{
The density of social networks moderates effects of intergroup contact
}

\author{
Tobias H. Stark \\ Utrecht University/ICS, Padualaan 14, 3584 CH Utrecht, The Netherlands
}

\section{A R T I C L E I N F O}

\section{Article history:}

Received 5 February 2016

Received in revised form 7 October 2016

Accepted 8 October 2016

Available online 31 October 2016

\section{Keywords:}

Intergroup contact

Social networks

Prejudice

Network density

\begin{abstract}
A B S T R A C T
This study tests how the density of the social network in which intergroup contact takes place might affect the extent to which contact improves intergroup attitudes. Having contact with more outgroup members in dense social networks, in which everybody knows each other, may reinforce contact's positive effect. In this case, outgroup contact is shared with ingroup members, which suggests positive ingroup norms toward the outgroup. Alternatively, more contact in denser networks may improve intergroup attitudes less because density may increase subtyping or reduce the salience of ethnic group memberships. These competing hypotheses are tested among white American adults in a nonprobability online sample $(N=305)$ and in a representative national sample $(N=1270)$. In both studies, contact is associated with more positive attitudes toward racial outgroups but the positive contact effect is weakened if that contact takes place in a denser social network.
\end{abstract}

(c) 2016 Elsevier Ltd. All rights reserved.

\section{Introduction}

Research on Allport's (1954) contact theory has repeatedly shown that having contact with members of other racial or ethnic groups (outgroups) reduces prejudice (Pettigrew \& Tropp, 2006; Pettigrew, Tropp, Wagner, \& Christ, 2011; Swart, Hewstone, Christ, \& Voci, 2011). Many of these previous studies determined the amount of intergroup contact a person had by counting up the number of outgroup members the person interacted with. However, social contacts are often not independent from each other but are connected within social networks (Merino, 2013; Pettigrew, Christ, Wagner, \& Stellmacher, 2007). This is particularly true for intergroup friendships, the most prominent indicator of intergroup contact (Davies, Tropp, Aron, Pettigrew, \& Wright, 2011). Very few studies have thus far considered inter-connectedness of intergroup contact in social networks (Munniksma, Stark, Verkuyten, Flache, \& Veenstra, 2013; Stark, 2015; Wölfer, Faber, \& Hewstone, 2015).

The present study argues that the effect of intergroup contact on intergroup attitudes might depend on the structure of the social network in which this contact takes place. Recent research has shown that contact effects are moderated by norms that are shared in a social network (Merino, 2013), but no research has looked at the structural features of the network. Particularly network density, the proportion of the members of a person's social network that are also related to each other (Wasserman \& Faust, 1994), may affect the outcome of intergroup contact because network density has been found to affect people's behavior, perceptions, and attitudes. Educational performance and depression, for example, are related to the density of a person's friendship network (Falci \& McNeely, 2009; Ryabov, 2009). People with denser networks are also more strongly influenced by the behavior of their friends (Haynie, 2001). Moreover, people with a more cohesive family network more strongly opposed the idea of interracial marriage than those with a less cohesive family network (Huijnk, Verkuyten, \&

E-mail address: t.h.stark@uu.nl 
Coenders, 2013). The effect of having contact with outgroup members on intergroup attitudes might likewise be moderated by the density of the social network in which this contact takes place. In the next section, different forms of network density are introduced. Subsequently, two sets of competing hypotheses about the potential effect of network density are presented and tested in two independent studies.

\subsection{Network density}

A person's social network that includes both ingroup and outgroup members allows different conceptualization of its density. The overall density simply takes into account what proportion of the members of a person's social network are related to each other, no matter if they belong to the person's ingroup or to the outgroup. For instance, if a white individual had six friends and four of these friends were also friends with each other while the other two were not friends with anyone else, the person's network would have a density of 0.4 . Six of the possible 15 friendship relationships $(6 / 15=0.4)$ between the six network members exist (Wasserman \& Faust, 1994).

If a person also has friends from another racial group, it is possible to calculate network density based only on relationships that include outgroup members. A measure that could be called cross-group density refers to the proportion of existing relationships between ingroup and outgroup members but excludes relationships between members of the same group. Thus, this measure captures how densely friends from the ingroup and outgroup are connected with each other. If in the given example, two of the white person's friends were black, there could be eight cross-group relationships in total because each of the two outgroup members could have a relationship with four ingroup members. If we assume that the two black friends are among the four friends that are also friends with each other, the cross-group density would be $4 / 8=0.5$. ${ }^{1}$

A slight variation of the cross-group density could be called the outgroup member density. This is the density of the sub-network that includes all potential relationships in which outgroup members are involved. This measure includes relationships among outgroup members and thus reflects how well outgroup members are embedded in a social network. In the given example, the two black outgroup members could form nine friendships with other people in the network (eight with the white friends and one relationship with each other). Since the two black people are among the four friends that are also friends with each other, the outgroup member density of this person's network would be $5 / 9=0.56$.

\subsection{Positive reinforcement of contact}

The density of a social network may reinforce positive contact effects. For instance, the friendship between a white and a black teenager might reduce racial prejudice more effectively if their friendship is embedded in a larger, closely-knit network of friends at football training than if the black and the white teenager do not share mutual friends. The positive experiences of the friendship between the two may be amplified and reinforced by the experiences they share as part of the network of the football team.

Hypothesis H1. a: The density of the social network in which contact takes place reinforces the positive effect of having more intergroup contact on more positive intergroup attitudes.

Such a reinforcing effect of network density is in line with the extended contact hypothesis, according to which the mere knowledge that ingroup friends have outgroup friends reduces prejudice (Wright, Aron, McLaughlin-Volpe, \& Ropp, 1997). In a dense network, people have direct contact with their outgroup friends and also extended contact through their ingroup friends who are also connected with the outgroup friends. ${ }^{2}$ More than 50 studies have convincingly shown that extended contact can have additional positive effects on intergroup attitudes in the presence of direct contact with outgroup members (Vezzali, Hewstone, Capozza, Giovannini, \& Wölfer, 2014).

For extended contact to underlie the reinforcing effect of network density, the density needs to capture relationships between ingroup and outgroup members of a person's social network (cross-group density). Such cross-group friendships of ingroup friends signal the existence of positive ingroup norms regarding the outgroup (Dovidio, Eller, \& Hewstone, 2011; Pettigrew et al., 2007), which have been identified as mediators of the extended contact effect (Cameron, Rutland, Hossain, \& Petley, 2011; Turner, Hewstone, Voci, \& Vonofakou, 2008; Visintin, Brylka, Green, Mähönen, \& Jasinskaja-Lahti, 2016). Positive ingroup norms indicate that people will not be sanctioned by ingroup members for the same behavior (Cialdini, Kallgren, \& Reno, 1991). Recent research found that (1) contact between people in a given social context led to positive ingroup norms toward the outgroup in that context and (2) that living in a social context with such positive ingroup norms had an additional positive effect on intergroup attitudes on top of the effect of direct contact with outgroup members (Christ et al., 2014).

Since positive ingroup norms develop through intergroup contact of ingroup members, network density can only signal the existence of such norms if it reflects relationships between ingroup and outgroup members.

\footnotetext{
1 A graphical illustration of the various density measures for the given example is shown in Online Appendix A.

2 An indirect relationship with an outgroup member through a shared ingroup friend is also considered extended contact even if there is a direct relationship with the same outgroup member as long as the effect of direct contact is statistically controlled (Vezzali et al., 2014).
} 
Hypothesis H1. $\quad b$ : The reinforcing effect of network density is driven by the cross-group density that captures relationships between ingroup and outgroup members.

\subsection{Undermining consequences of intergroup contact}

It is also possible that network density has the opposite effect and reduces the effectiveness of intergroup contact experiences. This could happen if people consider their well-embedded outgroup contacts as less representative of the outgroup and thus not informative about other members of it. These people may 'subtype' out (Weber \& Crocker, 1983) their contacts who they do not consider typical members of the outgroup and thereby protect their perception of the outgroup (Hewstone, 1994). They may say, "Yes my two friends on the football team are Hispanic. But they are so well integrated into the team, which shows that they are much more American than Hispanic. Accordingly, knowing them provides no reason to change my perception of that group." This reasoning suggests an effect of network density that is the exact opposite of the effect proposed in H1a.

Hypothesis H2. $a$ : The density of the social network in which contact takes place weakens the effect of having more intergroup contact on more positive intergroup attitudes.

A dense network can only lead to subtyping if the outgroup members are closely connected to the ingroup members of a person's social network. If outgroup members have many relationships with fellow outgroup members, there is little reason to assume they are not representative of their racial group. However, if the black friend in the football team has only white friends in the team, s/he may not be considered a typical African American and may thus not affect his/her friends' attitudes toward blacks.

Hypothesis H2. $\quad b$ : The undermining effect of network density is driven by the cross-group density that captures relationships between ingroup and outgroup members.

Alternatively, a dense social network could undermine the positive effect of contact independently of with whom the outgroup members have relationships. The reason is that members of dense social networks probably know more about each other because many social contacts are shared. In such networks, people may meet each other more frequently, for example at their common friend's house or at football training. This means there are more opportunities to get individuating information from one's outgroup friends. Moreover, people can learn more about their outgroup contacts when they talk about their shared friends with other network members.

Research has shown that racial group boundaries become less salient if people have more individuating information about their contacts (Blair, 2002; Fiske, 1993). That is, people are more strongly inclined to think about outgroup members of whom they know a lot as individuals, and less as members of a certain racial group. If the group membership is not salient during intergroup contact, people are less likely to generalize from their positive attitudes toward the individual outgroup member to their attitudes toward the outgroup as a whole (Brown \& Hewstone, 2005; Hewstone \& Brown, 1986). If a denser network means that people gain more individuating information about their outgroup contacts, the salience of group memberships will be reduced, which undermines the positive effect of intergroup contact on intergroup attitudes. In this case, the undermining effect of network density should be driven by the outgroup member density that indicates how well outgroup members are embedded in a person's network, independently of whether these relationships are with ingroup or outgroup members.

Hypothesis H2. $c$ : The undermining effect of network density is driven by the outgroup member density that is based on all relationships including outgroup members.

\subsection{The present research}

A test of the competing hypotheses ( $\mathrm{H} 1 \mathrm{a}, \mathrm{H} 1 \mathrm{~b}$ versus $\mathrm{H} 2 \mathrm{a}, \mathrm{H} 2 \mathrm{~b}, \mathrm{H} 2 \mathrm{c}$ ) requires information on the structure of the network in which contact takes place. Few data sets contain this information along with questions on the racial composition of the network and intergroup attitudes. This research makes use of two so-called ego-centered network studies (Burt, 1984), in which survey respondents named up to five (Study 1 ) or up to six (Study 2) people they felt close to. Subsequently, respondents indicated the race of these people and whether these network contacts also knew each other.

The present research focuses on white majority group members contact with racial outgroup members in their social network. Both studies also included more traditional indicators of intergroup contact, which allows testing for convergent validity of these indicators and the network contact measure. Network density is derived from the questions about who in a person's network knows whom. Questions about the frequency of meeting the network members are used to test whether people with denser social networks meet their contacts more often. 


\section{Study 1}

\subsection{Method}

\subsubsection{Data}

Data were collected in a non-probability online sample of U.S. residents recruited through Amazon Mechanical Turk (MTurk). An invitation to participate in a survey about social relationships was published on MTurk on July 20, 2014 , and 468 respondents followed this invitation within three hours. Completing the survey took on average 6.1 min and respondents were paid \$1 for their participation. The present research only focused on the 342 respondents who identified as white (Caucasian). Twenty-six respondents failed an attention check at the end of the survey and were removed from the sample. ${ }^{3}$ Three additional respondents were excluded from the analyses due to missing values on the dependent variable and eight respondents were removed due to missing values on the political ideology variable. The remaining 305 respondents in the final sample were predominantly highly educated (48\% had a 4-year college degree) and male (55\%). The average age was 34.8 years.

\subsubsection{Central variables}

Attitudes toward blacks were measured at the end of the survey. Respondents were asked, "Do you feel warm, cold, or neither warm nor cold toward most black people?" Answers could be given on a 7-point scale ranging from "extremely cold" to "extremely warm."

To assess the social network, respondents were asked, "Who are the people outside of your home that you feel closest to? These may be friends, co-workers, neighbors, relatives, or anyone else who does not live with you. You can enter up to five people." Subsequently, it was asked for each contact in the network to which racial/ethnic group this person belonged. The number of black network members could thus range from 0 to 5 but the distribution was extremely skewed. Of the 305 respondents, 57 named one black network contact, 10 named two, and only one person named 5. To avoid wrong interpretations due to this skewed distribution, the contact variable was dummy coded indicating whether a respondent had 0 or at least one (coded 1 ) black network member. ${ }^{4}$ A total of $22.3 \%$ of respondents had at least one black contact. Unfortunately, having barely variance in the amount of intergroup contact prohibits separate analyses of cross-group density and outgroup member density among respondents who have at least one outgroup contact. Study 1 is thus limited to the analysis of overall density.

Overall network density was calculated as the number of connections between network members divided by the number of potential relationships between all network members (Wasserman \& Faust, 1994). There were two versions of the questionnaire and the way in which relationships between network contacts could be indicated differed between these versions. Half of the sample was asked to either say "yes" or "no" to a set of questions that asked for each pair of network contacts "Does [name 1] know [name 2]?" The other half of the sample completed the questionnaire with a graphical tool called GENSI (Graphical Ego-centered Network Survey Interface) in which each contact's name was displayed in a circle on the screen (Stark \& Krosnick, 2017). Respondents could click on the name of one person and then on the name of another person to create a line between the two circles. The number of lines indicated the number of relationships in the network. Seeing a traditional questionnaire or GENSI did not affect the network composition, respondents' attitudes toward blacks, or the interaction effect between network density and having black contacts.

\subsubsection{Additional variables}

For each network contact, respondents could indicate how often they talked with each other. Frequency of interacting was coded 1 "less than once a month," 2 "at least once a month," 3 "at least once a week," and 4 "every day, or almost every day." To test for convergent validity of the network contact measure and a more traditional contact indicator, respondents were asked, "About how many of your friends are black?" Response options were 1 "none," 2 "a few," 3 "about half," 4 "most," and 5 “all” (Tausch, Hewstone, Schmid, Hughes, \& Cairns, 2011).

\subsubsection{Control variables}

Respondents' age, sex, political ideology, and the size of their network were included as control variables. Because there were extremely few low educated respondents, education was dummy coded, differentiating between those who had at least a four-year college degree and those who did not. Political ideology was measured with the question, "Generally speaking, do you consider yourself. .." Answers were coded to range from 1 "very liberal" to 5 "very conservative." To control for the possibility that people with different numbers of contacts in their network differed in their attitudes toward blacks, the size of the ego-centered network was added to the models.

\footnotetext{
${ }^{3}$ This made sure that only respondents who actually read the survey instructions were included. The attention check question simply asked respondents to click on the fourth response option. Everybody who failed to do so was removed from the sample.

${ }^{4}$ A replication of the analysis with a metric indicator for the number of black network contacts yielded similar results (see Online Appendix B).
} 
Table 1

Descriptive Statistics for all Variables in Study 1.

\begin{tabular}{|c|c|c|c|c|}
\hline Variables & Mean / \% & S.D. & Values & Valid N \\
\hline \multicolumn{5}{|l|}{ Central variables } \\
\hline - Black feeling thermometer & 4.83 & 1.17 & $1-7$ & 313 \\
\hline - Black contacts (yes) & $22 \%$ & & $0 / 1$ & 316 \\
\hline - Overall network density & 0.59 & 0.31 & $0-1$ & 316 \\
\hline \multicolumn{5}{|l|}{ Additional variables } \\
\hline - Traditional contact & 1.80 & 0.52 & $1-5$ & 316 \\
\hline - Frequency of interacting with network members & 3.01 & 0.60 & $1-4$ & 305 \\
\hline \multicolumn{5}{|l|}{ Control variables } \\
\hline - Network size ( $\mathrm{N}$ of people in the network) & 4.50 & 0.99 & $1-5$ & 316 \\
\hline - Age & 34.81 & 12.11 & $19-74$ & 316 \\
\hline - Sex $(0=$ female, $1=$ male $)$ & $55 \%$ & & $0 / 1$ & 316 \\
\hline - Education ( 1 = 4-year college degree) & $48 \%$ & & $0 / 1$ & 316 \\
\hline - Political ideology ( 1 = very liberal, 5 = very conservative) & 2.37 & 1.04 & $1-5$ & 307 \\
\hline
\end{tabular}

Table 2

Correlations of all Variables in Study 1.

\begin{tabular}{|c|c|c|c|c|c|c|c|c|c|}
\hline Variables & 1 & 2 & 3 & 4 & 5 & 6 & 7 & 8 & 9 \\
\hline 1. Black feeling thermometer & 1.00 & & & & & & & & \\
\hline 2. Black contacts & $0.18^{* *}$ & 1.00 & & & & & & & \\
\hline 3. Overall density & 0.001 & -0.03 & 1.00 & & & & & & \\
\hline 4. Traditional contact & $0.21^{* * *}$ & $0.37^{* * *}$ & $0.12^{*}$ & 1.00 & & & & & \\
\hline 5. Frequency of interacting & 0.08 & $0.17^{* *}$ & $0.19^{* * *}$ & 0.10 & 1.00 & & & & \\
\hline 6. Network size & 0.06 & 0.03 & $-0.19^{* * *}$ & 0.09 & $-0.17^{* *}$ & 1.00 & & & \\
\hline 7. Age & 0.08 & $-0.12^{*}$ & -0.10 & -0.08 & $-0.16^{* *}$ & -0.01 & 1.00 & & \\
\hline 8. Sex (male) & $-0.18^{* *}$ & 0.10 & $0.14^{*}$ & 0.04 & 0.04 & 0.05 & $-0.17^{* *}$ & 1.00 & \\
\hline 9. Education (4-year college) & 0.02 & -0.09 & 0.09 & -0.03 & -0.07 & 0.04 & 0.01 & $-0.12^{*}$ & 1.00 \\
\hline 10. Political ideology (conservative) & $-0.16^{* *}$ & 0.03 & 0.05 & -0.01 & 0.11 & 0.10 & 0.09 & $0.14^{*}$ & -0.12 \\
\hline
\end{tabular}

Note. Pairwise deletion of missing values.

*** $p<0.001$.

*** $p<0.01$.

$p<0.05$ (two-tailed tests).

\subsection{Results}

Respondents held relatively warm feelings toward blacks. The mean value of the feeling thermometer $M=4.83$ (Table 1 ) was significantly larger than the mid-point of 4 , which indicated "neither warm nor cold" $t(304)=12.22, p<0.001, d=1.40$. The mean overall network density of 0.59 was significantly larger than $0.5 t(304)=5.28, p<0.001, d=0.61$, which would indicate that half of all network members knew each other.

Respondents' attitudes toward blacks were significantly and positively correlated with having black contacts $(r=0.18$, $p=0.001$, Table 2 ) but did not correlate with the overall network density measure $(r=0.001, p=0.987)$. Having black contacts was also positively correlated with the traditional contact measure $(r=0.37, p<0.001)$. This indicates convergent validity between the network contact indicator and the more traditional measure. Overall density correlated positively with the average frequency of interacting with the member of one's network $(r=0.19, p<0.001)$. This is in line with the idea that people might receive more information about their outgroup friends in a denser network.

In an OLS regression, the black feeling thermometer was significantly predicted by respondents' sex and political ideology (Table 3). Men held less positive attitudes toward blacks ( $b=-0.39, p=0.004$, Model 1 ) and so did respondents with a more conservative political ideology $(b=-0.18, p=0.004)$. Unsurprisingly, giving the young and highly educated sample, age and education were not significant predictors of respondents' feeling toward blacks. Respondents who had at least one black person in their ego-centered network had significantly more positive attitudes toward blacks than those without black network contacts $(b=0.60, p<0.001)$.

The positive effect of having black network contacts on respondents' feelings toward blacks was significantly reduced by the density of the network in which this contact took place. The interaction between overall network density and having at least one black network contact was negative and significant $(b=-1.12, p=0.031$, Model 2$)$. Fig. 1 shows predicted values of this interaction for respondents with a network of low density (one standard deviation below the mean) and high density (one standard deviation above the mean). Simple slope analysis (Aiken \& West, 1991) indicated that the net effect of having at least one versus no black contact was significant and positive for people who had a network with a low density (simple slope: $b=0.93, S E=0.22, p<0.001$ ). The net effect of having at least one black contact was not significant for people with a network of high density (simple slope: $b=0.23, S E=0.23, p=0.31$ ). Thus, the positive effect of having at least one black network members on respondents' feelings toward blacks can only be observed in social networks with a low density. This is in line with Hypothesis $\mathrm{H} 2 \mathrm{a}$ and rejects Hypothesis H1a. 
Table 3

Unstandardized OLS Coefficients Predicting Attitudes toward Blacks (feeling thermometer) in Study 1 (N=305).

\begin{tabular}{|c|c|c|c|c|}
\hline \multirow[b]{2}{*}{ Variables } & \multicolumn{2}{|c|}{ Model 1} & \multicolumn{2}{|c|}{ Model 2} \\
\hline & $b$ & S.E. & $b$ & S.E. \\
\hline Intercept & $4.47^{* * *}$ & 0.42 & $4.33^{* * *}$ & 0.42 \\
\hline \multicolumn{5}{|l|}{ Controls } \\
\hline - Network size & 0.10 & 0.07 & 0.10 & 0.07 \\
\hline - Age & 0.01 & 0.01 & 0.01 & 0.01 \\
\hline - Gender (male) & $-0.39^{* *}$ & 0.14 & $-0.40^{* *}$ & 0.13 \\
\hline - Education (4-year college) ${ }^{a}$ & -0.03 & 0.13 & -0.04 & 0.13 \\
\hline - Political ideology (conservative) & $-0.18^{* *}$ & 0.06 & $-0.18^{* *}$ & 0.06 \\
\hline \multicolumn{5}{|l|}{ Network } \\
\hline - Overall density & 0.27 & 0.21 & $0.49^{*}$ & 0.24 \\
\hline - Black contacts & $0.60^{* * *}$ & 0.16 & $1.25^{* * *}$ & 0.34 \\
\hline - Overall density x black contacts & - & & $-1.12^{*}$ & 0.52 \\
\hline Adjusted $R^{2}$ & 0.08 & & 0.09 & \\
\hline
\end{tabular}

Note. ${ }^{\text {a}}$ Education: less than 4 -year college degree is reference category.

*** $p<0.001$.

** $p<0.01$.

* $p<0.05$ (two-tailed tests).

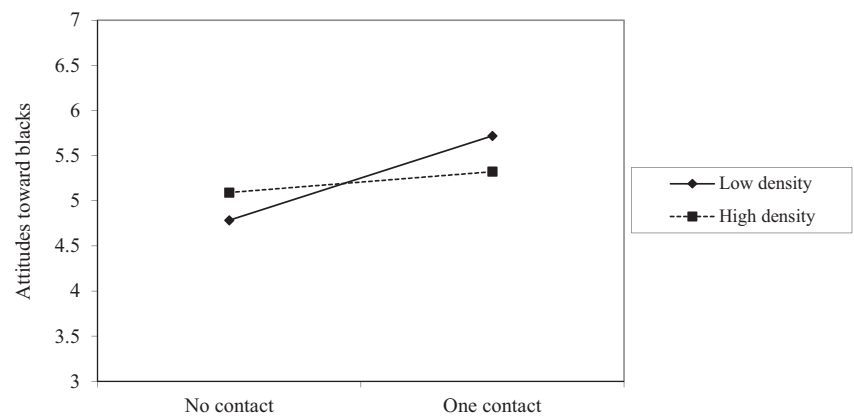

Fig. 1. Relationship between having None or At Least One Black Contact and Attitudes toward Blacks (Feeling Thermometer) depending on Network Density in Study 1 (Predicted Values).

Note. Control variables are either fixed to the sample mean or to the reference category.

\subsection{Discussion}

Results of Study 1 suggest that intergroup contact is less strongly related to positive intergroup attitudes when it takes place in denser social networks. In line with contact theory (Allport, 1954), white respondents felt more positively toward blacks when they had black contacts in their social network. This effect was weakened when these black contacts were part of denser social networks in which more network members knew each other. This leads to a rejection of Hypothesis H1a, which suggested that positive contact effects would be reinforced in a denser network.

The design of Study 1 limits the confidence with which Hypothesis H1a can be rejected. First, this study only asked for attitudes toward blacks, which raises the question whether the findings generalize to other groups. Second, Study 1 was implemented with MTurk participants, who are not representative of any population. It remains thus unclear how well the present results generalize to other potential respondents. Third, the limited amount of black network contacts in the sample forced the use of a dummy variable, which is accompanied by a loss of information.

Most problematic, little variation in the amount of intergroup contact prohibited separate analyses for cross-group density and outgroup member density in Study 1. However, all theoretical arguments for an effect of the network structure rely on relationships of outgroup members with other network contacts. It is unclear how well the overall density reflects these relationships because this measure also includes relationships between ingroup members. A larger sample, in which contact with more racial outgroups is measured, might allow testing whether the negative moderation observed in this study is due to outgroup members' relationships with ingroup members (H2b) or their relationships with any member of the network $(\mathrm{H} 2 \mathrm{c})$.

\section{Study 2}

To overcome the limitations of Study 1, Study 2 makes use of a large sample that is representative of the U.S. population. White respondents' contact with members of various racial and ethnic groups is related to the only available indicator of intergroup attitudes in this study, respondents' attitudes toward interracial marriage. People's support of interracial marriage 
is considered one of the strongest indicators of positive interracial attitudes (Allport, 1954). In fact, interracial marriage has been called the "ultimate break with traditional racial norms" (Johnson \& Jacobson, 2005; p. 387), and it thus represents the last step on Bogardus' (1933) social distance scale. Previous research has found that interracial contact improves attitudes toward interracial marriage (Johnson \& Jacobson, 2005; Perry, 2013).

\subsection{Method}

\subsubsection{Data}

Analyses are based on the 2006 Portraits of American Life Study (Emerson \& Sikkink, 2006). A U.S. nationally representative random sample of 2610 adults was interviewed in their home (response rate $=58 \%$ ). ${ }^{5}$ Respondents were paid $\$ 50$ to participate in an 80-min computer-assisted interview. To increase privacy, some responses were directly entered into the computer by the respondents using an audio computer-assisted self-interviewing (ACASI) device. Data were collected by RTI International, which also provided weights to account for planned unequal probability of selection and to post-stratify the data to match population statistics provided by the American Community Survey. Details on the methodology and sampling strategy are given in Emerson, Sikkink, and James (2010). The present study focuses on the 1270 white, non-Hispanic respondents who gave a valid answer to the dependent variable attitudes toward interracial marriage (of originally 1292 respondents).

\subsubsection{Central variables}

To measure attitudes toward interracial marriage, respondents were asked using ACASI, "In general, how comfortable or uncomfortable would you be if your daughter married someone who is Asian?" The same question was asked for the groups "Hispanic or Latino" and "black or African American." Answers were given on a 5-point scale ranging from "very uncomfortable" to "very comfortable." The three questions showed good internal consistency (Cronbach's alpha $=0.87$ ). Attitudes toward interracial marriage were measured as the mean over the non-missing answers to the three questions with higher values indicating more positive attitudes. 133 respondents who answered, "it depends" to all three questions were recoded to "somewhat comfortable". The answer "it depends" may in fact suggest that these people are reasonably tolerant racially but are thinking of other matters such as education or social class that may also affect their judgment. Race in itself seems to be not enough reason for these respondents to oppose the idea of an interracial marriage. ${ }^{6}$

Just as all other independent variables, questions about a respondent's social network were asked by an interviewer and not directly entered by the respondents. All respondents were asked, "Now think about the persons outside your home that you feel closest to. These may be friends, coworkers, neighbors, relatives or anyone else who does not live here. Not including people living in your home, about how many people, if any, would you say you feel close to?" Respondents who indicated to feel close to at least one person were subsequently asked, "I want to ask a series of questions about the people you feel closest to - up to four people. So I can ask about the right person, please give me the first name or initials of the person outside of your home you feel closest to." This question was repeated for up to four people.

Respondents who were a member of a congregation were additionally asked, "We would like to add two names from your congregation - not including your parents, siblings, or children. Besides those already mentioned, what is the first name or initials of the person you are closest to at your congregation?" A person's social network in the present study could thus consist of four or six people. For these up to six network contacts, respondents were asked, "Which of these are a different race than you?" The analyses below were performed separately for people who could name six and for respondents who could name only four network contacts. Of the 647 white respondents who could name six contacts, $120(18.5 \%)$ named at least one non-white contact they felt close to. Of the 623 respondents with four network contacts, $118(18.9 \%)$ named a non-white person.

Overall density was calculated separately for respondents who were asked to name six contacts and those who were asked for only four names. The calculation was done in the same way as in Study 1 and it was based on answers to the question "Which of the following, if any, does [Name 1] know?" Respondents indicated which other network members Person 1 knew. This was repeated for each person in the network.

To calculate the cross-group density, the number of existing relationships between white network members and nonwhite network members was divided by the number of potential relationships between the two groups. This statistic and the next one can only be calculated for people who have at least one non-white network contact $(n=120$ who could name six network contacts and $n=118$ who could name four network contacts).

To calculate the outgroup member density, the number of network members that were known by a non-white network member was divided by the number of network members the non-white network members could have known. Thus, relationships among the white network members were excluded from this measure.

\footnotetext{
${ }^{5}$ Note that this response rate corresponds most closely to the AAPOR Response Rate 3 (RR3), which assumes that the proportion of eligible households among those that were not reached is the same as among households that were reached. Other representative U.S. studies have similar response rates. For instance, RR 3 of the 2008 American National Election Study was 63.7\%.

${ }^{6}$ A replication of all analyses in which respondents who said "it depends" were recoded to missing values yielded similar results (see Online Appendix C).
} 


\subsubsection{Additional variables}

To test whether people in a denser network are encountered more frequently, the frequency of interacting was coded for each network contact. In two questions, respondents were asked with which network contact they interacted in person once a week or more and with which contact they interacted in person at least once a month or more. The frequency of interacting was coded 1 if a network contact was not nominated in either of these two questions, indicating that they interacted in person less frequently than once a month. It was coded 2 if the respondent indicated to interact at least once a month with the network contact and it was coded 3 if they interacted once a week or more.

The study included also two more traditional indicators of contact that allowed validating the network measure of contact. The frequency of visits of non-white friends was measured by the question, "In the past 12 months, about how many times have you been in the home of a friend of a different race or had them in your home?" Response options ranged from "never" to "more than once a week." Answers were coded to range from 0 to 7 , with high values indicating more visits. Separate questions were asked to measure the frequency of conversations with blacks, Asian, and Hispanic. "Now think about conversations you have had with different types of people in the past 12 months. How often do you have a conversation with someone who, as far as you know, is [group]?" Answer options ranged from "never" to "every day" and were coded to range from 0 to 6 so that higher values indicate more conversations. Conversation frequency with non-white people was calculated as the average of answers given to all three questions.

\subsubsection{Control variables}

Next to their age and gender, respondents were also asked, "Do you have any children living with you, including adopted and step-children?" and, "Do you have any children not living with you, including adopted and step-children?" A dummy variable was generated indicating whether the respondents had children because the dependent variable is about the potential interracial marriage of a respondent's daughter. It was not asked for the gender of respondents' children. Four dummy variables were generated based on the question, "What is the highest level of schooling you have completed, or what is the highest degree that you have earned?" Education variables indicated whether respondents had no high school diploma (8\%), finished high school (42\%), had some college education (20\%), or had a college degree or higher (31\%). Thirty-nine respondents refused to answer this question. Because people in the Western United States tend to have more liberal views on interracial relationships (Johnson \& Jacobson, 2005; Perry, 2013), four dummy indicators for respondents' geographic location were added. Partisanship was based on answers to the question, "In politics, do you usually think of yourself as a Democrat, a Republican or an Independent?" Answers ranged from 0 “strong Republican" over 3 "Independent" to 6 "strong Democrat." Fifty-two respondents did not answer this question.

\subsubsection{Analytical strategies}

Missing values on all independent variables were imputed using multiple imputation with a multivariate normal model (StataCorp, 2013). Missing values on the dependent variables were not imputed (22 cases were removed). This resulted in the final sample sizes of $N=647$ respondents who could name six network contacts and $N=623$ respondents who could name four network contacts. Data were weighted to adjust for sampling design and post-stratified to match American Community Survey statistics in the complete sample (Emerson et al., 2010). Clustering in primary sampling units was accounted for.

\subsection{Results}

Respondents in both subsamples felt slightly more comfortable than uncomfortable with the idea of their daughter marrying someone of another race (Table 4). The means of attitudes toward interracial marriage were significantly higher than the neutral mid-point of the answer scale (network size $6: M=3.17, F(1,646)=7.60, p=0.008, d=0.22$; network size 4: $M=3.23, F(1,622)=13.44, p<0.001, d=0.29)$ and not significantly different between the two subsamples $(F(1,1269)=0.71$, $p=0.41$ ). The overall density in both subsamples was significantly larger than 0.5 (network size $6: M=0.54, F(1,646)=4.20$, $p=0.045, d=0.16$; network size $4: M=0.61, F(1,622)=34.99, p<0.001, d=0.47)$ but the smaller networks were significantly denser than the larger networks $(F(1,1269)=14.22, p<0.001)$.

Respondents who were members of a congregation and could thus name six network contacts were older $(F(1$, $1269)=10.48, p=0.002, d=0.18)$, more likely to be female $(F(1,1269)=33.57, p<0.001, d=0.34)$, more likely to have children $(F(1,1269)=9.11, p=0.006, d=0.17)$ and more likely to consider themselves Republicans $(F(1,1269)=19.78, p<0.001$, $d=0.25$ ) than respondents who could only name four contacts. Remarkably, there was no significant difference in the number of non-white contacts although respondents in one subsample could nominate two more people (network size 6: $M=0.22$, network size 4: $M=0.26, F(1,1269)=0.68, p=0.41$ ) (Table 4).

In both subsample, attitudes toward interracial marriage were significantly and positively correlated with the number of non-white contacts in the network (network size 6: $r=0.10, p<0.001$, Table 5 below the diagonal, first column; network size 4: $r=0.11, p<0.001$, Table 5 above the diagonal, first row), and also with the more traditional contact variables frequency of visits of non-white friends (network size 6: $r=0.17, p<0.001$, Table 5, first column; network size 4: $r=0.21, p<0.001$, Table 5 first row) and conversation frequency with non-white people (network size 6: $r=0.15, p<0.001$, Table 5, first column; network size 4: $r=0.14, p<0.001$, Table 5 first row).

Significant and positive correlations between the number of non-white social network members and the frequency of visits of friends from a different race (network size 6: $r=0.31, p<0.001$, Table 5 , second column; network size 4: $r=0.34$. 
Table 4

Descriptive Statistics for all Variables in Study 2.

\begin{tabular}{|c|c|c|c|c|c|c|c|}
\hline \multirow[b]{2}{*}{ Variables } & \multicolumn{3}{|c|}{ Could name 6 network contacts $(N=647)$} & \multicolumn{4}{|c|}{ Could name 4 network contacts $(N=623)$} \\
\hline & Mean/\% & S.D. & Valid $N$ & Mean/\% & S.D. & Valid $N$ & Values \\
\hline \multicolumn{8}{|l|}{ Central variables } \\
\hline - Attitudes toward interracial marriage & 3.17 & 0.97 & 647 & 3.23 & 0.97 & 623 & $1-5$ \\
\hline - $N$ of non-white contacts (network members) & 0.22 & 0.54 & 647 & 0.26 & 0.55 & 623 & $0-6$ \\
\hline - Overall network density & 0.54 & 0.24 & 647 & 0.61 & 0.31 & 623 & $0-1$ \\
\hline - Cross-group density & 0.39 & 0.31 & 120 & 0.42 & 0.33 & 118 & $0-1$ \\
\hline - Outgroup member density ${ }^{a}$ & 0.41 & 0.30 & 120 & 0.46 & 0.33 & 118 & $0-1$ \\
\hline \multicolumn{8}{|l|}{ Additional variables } \\
\hline - Frequency of visits of non-white friend & 2.28 & 1.75 & 646 & 2.47 & 1.87 & 623 & $0-7$ \\
\hline - Conversation frequency with non-white people & 3.17 & 1.50 & 647 & 3.05 & 1.55 & 623 & $0-6$ \\
\hline - Frequency of interacting with network contacts & 2.26 & 0.44 & 647 & 2.19 & 0.51 & 590 & $1-3$ \\
\hline \multicolumn{8}{|l|}{ Control variables } \\
\hline - Network size ( $N$ of people in the network) & 5.33 & 0.86 & 647 & 3.55 & 0.91 & 623 & $0-6$ \\
\hline - Age & 48.54 & 13.97 & 647 & 44.92 & 13.84 & 623 & $18-80$ \\
\hline - Sex (male) & $39 \%$ & & 647 & $58 \%$ & & 623 & $0 / 1$ \\
\hline - Has children & $77 \%$ & & 647 & $68 \%$ & & 623 & $0 / 1$ \\
\hline - Education: less than high school & $4 \%$ & & 627 & $12 \%$ & & 604 & $0 / 1$ \\
\hline - Education: high school & $41 \%$ & & 627 & $44 \%$ & & 604 & $0 / 1$ \\
\hline - Education: some college & $20 \%$ & & 627 & $19 \%$ & & 604 & $0 / 1$ \\
\hline - Education: college degree & $35 \%$ & & 627 & $25 \%$ & & 604 & $0 / 1$ \\
\hline - Region: West & $20 \%$ & & 647 & $30 \%$ & & 623 & $0 / 1$ \\
\hline - Region: Northeast & $19 \%$ & & 647 & $14 \%$ & & 623 & $0 / 1$ \\
\hline - Region: Midwest & $29 \%$ & & 647 & $25 \%$ & & 623 & $0 / 1$ \\
\hline - Region: South & $32 \%$ & & 647 & $30 \%$ & & 623 & $0 / 1$ \\
\hline - Partisanship (6 = strong Democrat) & 2.68 & 1.80 & 624 & 3.32 & 1.59 & 594 & $0-6$ \\
\hline
\end{tabular}

Note. Weighted results.

a Cross-group density and outgroup member density could only be calculated for respondents with at least one non-white contact $(n=120$ and $n=118$ ).

Table 5

Correlations of Central and Additional Variables in Study 2.

\begin{tabular}{|c|c|c|c|c|c|c|}
\hline & 1 & 2 & 3 & 4 & 5 & 6 \\
\hline 1. Attitudes interracial marriage & 1.00 & $0.11^{* *}$ & -0.03 & $0.21^{* * *}$ & $0.14^{* * *}$ & $-0.14^{* *}$ \\
\hline 2. $N$ of non-white contacts & $0.10^{* *}$ & 1.00 & -0.06 & $0.34^{* * *}$ & $0.20^{* * *}$ & $0.09^{*}$ \\
\hline 3. Overall density & $-0.12^{* *}$ & $-0.09^{*}$ & 1.00 & -0.04 & $-0.14^{* *}$ & $0.18^{* * *}$ \\
\hline 4. Visits of non-white friends & $0.17^{* * *}$ & $0.31^{* * *}$ & -0.06 & 1.00 & $0.38^{* * *}$ & $0.11^{* *}$ \\
\hline 5. Conversation frequency non-whites & $0.15^{* * *}$ & $0.25^{* * *}$ & $-0.13^{* *}$ & $0.38^{* * *}$ & 1.00 & 0.06 \\
\hline 6. Frequency of interacting & -0.07 & 0.07 & $0.23^{* * *}$ & 0.02 & 0.05 & 1.00 \\
\hline
\end{tabular}

Note. Respondents who could name six contacts below diagonal $(N=647)$; respondents who could name only four contacts above diagonal ( $N=623$ )

Weighted results. Pairwise deletion of missing values.

**** $p<0.001$

** $p<0.01$.

$p<0.05$ (two-tailed tests).

$p<0.001$, Table 5, second row) and the frequency of conversations with non-whites (network size $6: r=0.25$. $p<0.001$, Table 5, second column; network size 4: $r=0.20 . p<0.001$, Table 5, second row) indicated convergent validity between these different measures of intergroup contact.

Overall network density correlated positively with the average frequency of interacting with the member of one's network in both subsamples (network size 6: $r=0.23, p<0.001$, Table 5, third column; network size 4: $r=0.18, p<0.001$, Table 5, third row). This is again in line with the idea that people can receive more information about their outgroup friends in a denser network.

Among the small subsamples of those with at least one non-white network member (Table 6), neither cross-group density (network size 6: $r=-0.13, p=0.15$, below the diagonal, first column; network size 4: $r=0.06, p=0.31$, above the diagonal, first row) nor outgroup member density (network size 6: $r=-0.09, p=0.54$, first column; network size 4: $r=0.07, p=0.47$, first row) was significantly correlated with attitudes toward interracial marriage. These two forms of density were, however, extremely highly correlated with each other (network size 6: $r=0.94, p<0.001$, seventh column; network size 4: $r=0.90$, $p<0.001$, seventh row).

\subsubsection{Effects of overall network density}

Results from an OLS regression indicated that men felt less comfortable with their daughter marrying someone of another race than did women $(b=-0.23, p=0.038$, Table 7 , Model 1$)$ in the subsample of people who could name six network contacts. All other control variables were not significantly related to intergroup attitudes in the multivariate analysis. In line with 
Table 6

Correlations of Central and Additional Variables among Respondents with at Least One Non-White Contact in Study 2.

\begin{tabular}{|c|c|c|c|c|c|c|c|c|}
\hline & 1 & 2 & 3 & 4 & 5 & 6 & 7 & 8 \\
\hline 1. Attitudes interracial marriage & 1.00 & $0.18^{*}$ & 0.07 & $0.30^{*}$ & -0.03 & -0.01 & 0.06 & 0.07 \\
\hline 2. N of non-white contacts & $0.19^{*}$ & 1.00 & $0.25^{* *}$ & $0.25^{* *}$ & 0.03 & $0.20^{*}$ & -0.01 & $0.26^{* *}$ \\
\hline 3. Overall density & $-0.23^{*}$ & -0.05 & 1.00 & $0.26^{* *}$ & 0.05 & $0.43^{* * *}$ & $0.80^{* * *}$ & $0.90^{* * *}$ \\
\hline 4. Visits of non-white friends & 0.17 & 0.08 & 0.14 & 1.00 & 0.18 & 0.12 & $0.23^{* *}$ & $0.31^{* * *}$ \\
\hline 5. Conversation frequency non-whites & 0.10 & $0.18^{*}$ & -0.02 & $0.32^{* *}$ & 1.00 & 0.11 & 0.06 & 0.05 \\
\hline 6. Frequency of interacting & $-0.20^{*}$ & -0.13 & $0.32^{* *}$ & 0.01 & 0.11 & 1.00 & $0.41^{* * *}$ & $0.43^{* * *}$ \\
\hline 7. Cross-group density & -0.13 & -0.16 & $0.72^{* * *}$ & 0.16 & -0.07 & $0.20^{*}$ & 1.00 & $0.90^{* * *}$ \\
\hline 8. Outgroup member density & -0.09 & 0.02 & $0.78^{* * *}$ & 0.12 & -0.07 & $0.19^{*}$ & $0.94^{* * *}$ & 1.00 \\
\hline
\end{tabular}

Note. Respondents who could name six contacts below diagonal ( $n=120)$; respondents who could name only four contacts above diagonal ( $n=118$ ). Weighted results. Pairwise deletion of missing values.

*** $p<0.001$

** $p<0.01$.

${ }^{*} p<0.05$ (two-tailed tests).

Table 7

Unstandardized OLS Coefficients Predicting Attitudes toward Interracial Marriage in Study 2.

\begin{tabular}{|c|c|c|c|c|c|c|c|c|}
\hline \multirow[b]{3}{*}{ Variables } & \multicolumn{4}{|c|}{ Could name 6 network contact $(N=647)$} & \multicolumn{4}{|c|}{ Could name 4 network contacts $(N=623)$} \\
\hline & \multicolumn{2}{|c|}{ Model 1} & \multicolumn{2}{|c|}{ Model 2} & \multicolumn{2}{|c|}{ Model 3} & \multicolumn{2}{|c|}{ Model 4} \\
\hline & $b$ & S.E. & $b$ & S.E. & $b$ & S.E. & $b$ & S.E. \\
\hline Intercept & 3.83 & 0.49 & 3.79 & 0.50 & 3.48 & 0.31 & 3.49 & 0.32 \\
\hline $\begin{array}{l}\text { Controls } \\
\text { - Network size } \\
\text { - Age } \\
\text { - Sex (male) } \\
\text { - Has children }\end{array}$ & $\begin{array}{c}-0.08 \\
-0.005 \\
-0.23^{*} \\
0.13\end{array}$ & $\begin{array}{l}0.05 \\
0.004 \\
0.11 \\
0.15\end{array}$ & $\begin{array}{c}-0.08 \\
-0.005 \\
-0.23^{*} \\
0.12\end{array}$ & $\begin{array}{l}0.05 \\
0.004 \\
0.11 \\
0.15\end{array}$ & $\begin{array}{l}-0.01 \\
-0.003 \\
-0.27^{* *} \\
-0.01\end{array}$ & $\begin{array}{l}0.06 \\
0.003 \\
0.09 \\
0.10\end{array}$ & $\begin{array}{l}-0.01 \\
-0.003 \\
-0.27^{* *} \\
-0.01\end{array}$ & $\begin{array}{l}0.06 \\
0.003 \\
0.10 \\
0.10\end{array}$ \\
\hline $\begin{array}{l}\text { - Education }{ }^{\mathrm{a}} \\
\text { - High school } \\
\text { - Some college } \\
\text { - College or more }\end{array}$ & $\begin{array}{l}0.10 \\
0.12 \\
0.36\end{array}$ & $\begin{array}{l}0.29 \\
0.29 \\
0.29\end{array}$ & $\begin{array}{l}0.11 \\
0.12 \\
0.37\end{array}$ & $\begin{array}{l}0.28 \\
0.28 \\
0.29\end{array}$ & $\begin{array}{l}0.08 \\
0.12 \\
0.33\end{array}$ & $\begin{array}{l}0.22 \\
0.23 \\
0.20\end{array}$ & $\begin{array}{l}0.08 \\
0.12 \\
0.33\end{array}$ & $\begin{array}{l}0.22 \\
0.23 \\
0.20\end{array}$ \\
\hline $\begin{array}{l}\text { - Region }{ }^{\mathrm{b}} \\
\text { - Northeast } \\
\text { - Midwest } \\
\text { - South } \\
\text { - Partisanship }\end{array}$ & $\begin{array}{c}0.16 \\
-0.03 \\
-0.05 \\
-0.002\end{array}$ & $\begin{array}{l}0.15 \\
0.16 \\
0.18 \\
0.02\end{array}$ & $\begin{array}{l}0.15 \\
-0.04 \\
-0.05 \\
-0.001\end{array}$ & $\begin{array}{l}0.15 \\
0.16 \\
0.18 \\
0.02\end{array}$ & $\begin{array}{l}-0.22 \\
-0.53^{* * *} \\
-0.21 \\
0.03\end{array}$ & $\begin{array}{l}0.16 \\
0.11 \\
0.11 \\
0.03\end{array}$ & $\begin{array}{l}-0.22 \\
-0.53^{* * *} \\
-0.21 \\
0.03\end{array}$ & $\begin{array}{l}0.16 \\
0.11 \\
0.11 \\
0.03\end{array}$ \\
\hline $\begin{array}{l}\text { Network } \\
\text { - } N \text { contacts (non-white) } \\
\text { - Overall density } \\
\text { - Overall density } \times N \text { contacts } \\
\text { Adjusted } R^{2}\end{array}$ & $\begin{array}{l}0.18^{* *} \\
-0.43 \\
- \\
0.06\end{array}$ & $\begin{array}{l}0.06 \\
0.22\end{array}$ & $\begin{array}{r}0.38^{* *} \\
-0.35 \\
-0.43^{*} \\
0.06\end{array}$ & $\begin{array}{l}0.11 \\
0.23 \\
0.19\end{array}$ & $\begin{array}{l}0.12 \\
0.06 \\
- \\
0.07\end{array}$ & $\begin{array}{l}0.07 \\
0.11\end{array}$ & $\begin{array}{l}0.10 \\
0.05 \\
0.03 \\
0.07\end{array}$ & $\begin{array}{l}0.16 \\
0.13 \\
0.23\end{array}$ \\
\hline
\end{tabular}

Note. Weighted results.

*** $p<0.001$

** $p<0.01$.

${ }^{*} p<0.05$ (two-tailed tests).

a Education: less than high school is reference category.

b Region: west is reference category.

contact theory, those with more non-white contacts in their social network felt more comfortable with the idea of interracial marriage $(b=0.18 p=0.002)$.

The interaction between overall network density and the number of non-white contacts in the network was significant but negatively related to attitudes toward interracial marriage ( $b=-0.43, p=0.029$, Table 7 , Model 2$)$. Simple slope analysis indicated that the net effect of having many non-white contacts in the network (three contacts versus one contact) was related to more positive attitudes toward interracial marriage if these contacts were part of a less dense network (one standard deviation below the mean, simple slope: $b=0.25, S E=0.07, p<0.001$ ). In a densely connected network (one standard deviation above the mean), the net effect of having three versus one non-white contact was not significant (simple slope: $b=0.04, S E=0.09, p=0.64)$. This suggests that the positive effect of additional intergroup contact is weakened by a denser social network. This refutes Hypothesis H1a and gives support to Hypothesis H2a.

Results were different for the subsample of respondents who could name only four network contacts. The number of nonwhite contacts in the network was not significantly related to respondents' attitudes toward interracial marriage (Table 7 , 
Table 8

Unstandardized OLS Coefficients Predicting Attitudes toward Interracial Marriage among Respondents with At Least One Non-White Network Contact in Study 2.

\begin{tabular}{|c|c|c|c|c|c|c|c|c|}
\hline \multirow[b]{3}{*}{ Variables } & \multicolumn{4}{|c|}{ Could name 6 network contact $(n=120)$} & \multicolumn{4}{|c|}{ Could name 4 network contacts ( $n=118$ ) } \\
\hline & \multicolumn{2}{|c|}{ Model 1} & \multicolumn{2}{|c|}{ Model 2} & \multicolumn{2}{|c|}{ Model 3} & \multicolumn{2}{|c|}{ Model 4} \\
\hline & $b$ & S.E. & $b$ & S.E. & $b$ & S.E. & $b$ & S.E. \\
\hline Intercept & 3.13 & 0.35 & 2.93 & 0.39 & 3.01 & 0.28 & 2.64 & 0.35 \\
\hline $\begin{array}{l}\text { Controls } \\
\text { - Sex (male) }\end{array}$ & -0.37 & 0.34 & -0.42 & 0.33 & -0.12 & 0.20 & -0.08 & 0.21 \\
\hline $\begin{array}{l}\text { - Region }{ }^{\mathrm{a}} \\
\text { - Northeast } \\
\text { - Midwest } \\
\text { - South }\end{array}$ & $\begin{array}{l}- \\
- \\
-\end{array}$ & & $\begin{array}{l}- \\
- \\
-\end{array}$ & & $\begin{array}{c}0.04 \\
-0.89^{*} \\
-0.06\end{array}$ & $\begin{array}{l}0.18 \\
0.40 \\
0.25\end{array}$ & $\begin{array}{c}0.04 \\
-0.86^{*} \\
-0.05\end{array}$ & $\begin{array}{l}0.17 \\
0.39 \\
0.25\end{array}$ \\
\hline $\begin{array}{l}\text { Network } \\
\text { - } N \text { contacts (non-white) } \\
\text { - Cross-group density } \\
\text { - Cross-group density } \times N \text { contacts } \\
\text { - Outgroup member density } \\
\text { - Outgroup member } \\
\text { Adjusted } R^{2}\end{array}$ & $\begin{array}{c}0.35^{* * *} \\
0.30 \\
-0.48 \\
- \\
- \\
0.09\end{array}$ & $\begin{array}{l}0.09 \\
0.74 \\
0.32\end{array}$ & $\begin{array}{l}0.53^{* * *} \\
- \\
- \\
0.47 \\
-0.62^{*} \\
0.09\end{array}$ & $\begin{array}{l}0.73 \\
0.29\end{array}$ & $\begin{array}{l}0.35^{\dagger} \\
0.38 \\
-0.15 \\
- \\
- \\
0.10\end{array}$ & $\begin{array}{l}0.20 \\
0.77 \\
0.47\end{array}$ & $\begin{array}{l}0.66^{* * *} \\
- \\
- \\
0.87 \\
-0.58^{\dagger} \\
0.11\end{array}$ & $\begin{array}{l}0.52 \\
0.32\end{array}$ \\
\hline
\end{tabular}

Note. Weighted results. Only control variables that were significant in Table 7 are included because of the small sample sizes.

a Region: west is reference category.

*** $p<0.001$.

** $p<0.01$.

$p<0.05$.

$\dagger p<0.1$ (two-tailed tests)

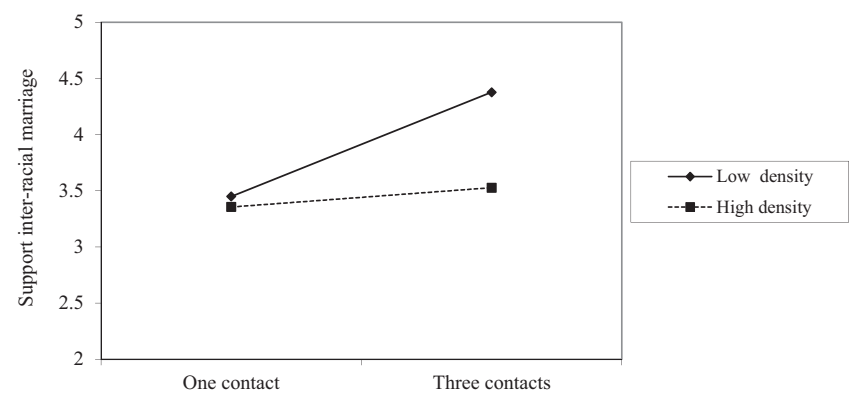

Fig. 2. Relationship between Few and Many Non-White Contacts and Attitudes toward Interracial Marriage depending on Outgroup-Member Density among Respondents who Could Name Six Contacts in Study 2 (Predicted Values).

Note. Control variables are fixed to the reference category.

Model 3). ${ }^{7}$ Next to respondents' sex $(b=-0.27, p=0.006)$, also the geographic region in which they lived was a significant predictor. People who lived in the Midwest had significantly less positive attitudes than people who lived in the Western USA $(b=-0.53, p<0.001)$. Moreover, the interaction between overall density and the number of contacts was not significant ( $b=0.03, p=0.90$, Table 7, Model 4). This suggests that, compared to people without non-white contacts in their network (reference category), having more of such contacts was not related to more positive attitudes toward interracial marriage and, accordingly, it did not matter how dense the network was in which this contact took place.

\subsubsection{Effects of cross-group and outgroup member density}

Separate models tested among respondents with at least one non-white network contact whether cross-group density or outgroup member density moderated the effect of intergroup contact. These models only included the control variables that were significant in the previous analysis because of the small sample sizes.

Cross-group density, which was based on all relationships between ingroup and outgroup members, did not moderate the effect of the number of non-white contacts among respondents who could name six network contacts $(b=-0.48, p=0.14$, Table 8, Model 1). This leads to rejection of both Hypothesis H1b and Hypothesis H2b. In contrast, the interaction between the outgroup member density and the number of non-white contacts was significant $(b=-0.62, p=0.036$, Table 8 , Model 2). Fig. 2 shows predicted values of this interaction. Simple slope analysis indicated that the net effect of three versus one

\footnotetext{
7 The number of non-white contacts turned significant when all insignificant control variables were removed from the model $(b=0.14, p=0.049)$.
} 


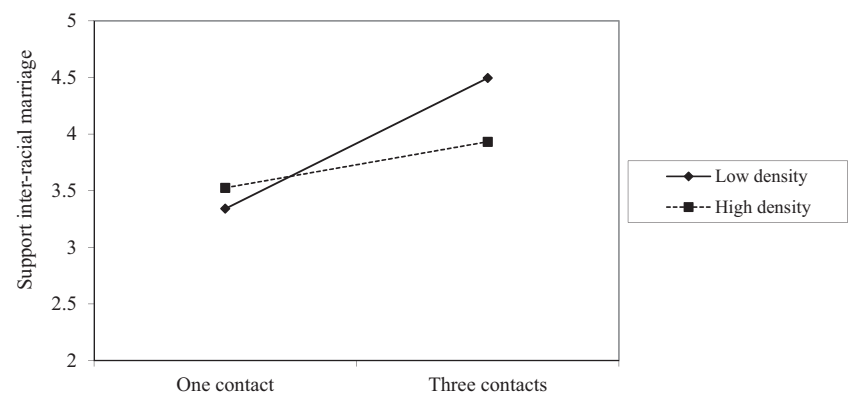

Fig. 3. Relationship between Few and Many Non-White Contacts and Attitudes toward Interracial Marriage depending on Outgroup-Member Density among Respondents who Could Name Four Contacts in Study 2 (Predicted Values).

Note. Control variables are fixed to the reference category.

contact was positive and significant in a network of low density (simple slope: $b=0.46, S E=0.12, p<0.001$ ) but not in a network of high density (simple slope: $b=0.09, S E=0.13, p=0.52$ ). This is in line with Hypothesis H2c.

Results were very similar for respondents who could name only four network contacts. The interaction between the number of non-white contacts and cross-group density did not predict attitudes toward interracial marriage $(b=-0.15$, $p=0.76$, Table 8 , Model 3$)$ but the interaction with outgroup member density was significant at the $p<0.1$ level $(b=-0.58$, $p=0.072$, Table 8 , Model 4 ). Fig. 3 shows predicted values of this interaction. Simple slope analysis indicated that the net effect of three versus one contact was positive and significant in a network of low density (simple slope: $b=0.58, S E=0.14$, $p<0.001$ ) but not in a network of high density (simple slope: $b=0.20, S E=0.15, p=0.176$ ). This is again in line with Hypothesis $\mathrm{H} 2 \mathrm{c}$ and suggests that the positive effect of intergroup contact is weaker if the outgroup contacts are closely connected with other members of a person's social network. ${ }^{8}$

\subsection{Discussion}

Results of Study 2 gave weak support for Hypotheses 2a and 2c, suggesting that intergroup contact is less strongly related to positive intergroup attitudes when it takes place in denser social networks. White respondents who could name six network contacts showed more support for interracial marriage the more non-white people they felt close to in their social network. This effect was significantly weakened when these non-white contacts were part of denser social networks in which most network members knew each other. The positive effect of having more non-white contacts did not replicate in the subsample of white respondents who could only name four network contacts due to the study design. Overall network density did also not appear to moderate this insignificant effect. Hypothesis H2a was thus supported in one of the two subsamples.

Consistent results emerged when respondents were removed from the sample who did not have intergroup contact at all. In line with contact theory (Allport, 1954), respondents with more non-white contacts in their social networks felt more at ease with interracial marriage in both subsamples. It turned out that the outgroup member density but not the crossgroup member density moderated this positive effect of intergroup contact in both subsamples. That is, the more densely the outgroup members were connected to both ingroup and outgroup members of a network, the weaker was the effect of knowing additional outgroup members on respondents' intergroup attitudes. This effect was significant among respondents who could name six network contacts and marginally significant among respondents who could name only four network contacts. This is in line with Hypothesis H2c.

\section{General discussion}

The present research presented some evidence in line with the new theoretical idea that the structure of the network in which intergroup contact takes place affects the consequences of this contact for intergroup attitudes. Highly significant correlations between different traditional intergroup contact measures in two independent studies and measures of contact derived from respondents' social networks provided evidence of convergent validity between the two types of indicators. Thus, contact that is measured in ego-centered networks is closely related to more traditional indicators of intergroup contact. In line with contact theory (Allport, 1954; Brown \& Hewstone, 2005), white respondents with more intergroup contact in their social network had more positive intergroup attitudes. There was no support for the hypothesis that positive contact

\footnotetext{
8 It may seem surprising that the cross-group density and outgroup member density have different effects given the high correlation between the two constructs ( $r=0.94$ and $r=0.90$, Table 6). However, the two forms of density were much less strongly correlated among respondents who had multiple outgroup members in their social network. The correlation was $r=0.72$ (network size 6 ) and $r=0.62$ (network size 4 ) among those who felt close to more than one non-white contact and it was $r=0.54$ (network size 6) and $r=0.21$ (network size 4 ) among those who had more than two non-white network members.
} 
effects would be reinforced in denser networks. Instead, results suggest that the effect of intergroup contact is weaker in denser social networks. In Study 1, it was found that having black network members was more strongly associated with more positive intergroup attitudes when these contacts were not part of a dense social network. In Study 2, the moderation effect of overall network density was also found among respondents who could name six network contacts but the interaction was insignificant among respondents who could name only for contacts.

Unfortunately, the available data did not allow a direct test of the proposed mechanisms underlying the potentially negative effect of network density. It could thus not be tested whether outgroup members in denser social network are subtyped out of their racial group because they are not considered representative of their group (Hewstone, 1994) or that higher density leads to more individuating information about the outgroup friend, which might reduce the salience of the outgroup membership (Blair, 2002; Fiske, 1993). However, respondents in both studies reported meeting their network contacts more frequently the denser their networks were. This is in line with the idea that higher density might increase the amount of individuating information people can gather about outgroup contacts. The more frequently people interact, the more knowledge they can gain about members of their network. This might reduce the salience of the outgroup members' racial group membership and thus weaken the effect of contact (Brown \& Hewstone, 2005; Hewstone \& Brown, 1986).

In line with the idea that network density might reduce intergroup contact's effect due to more individuating information, only the outgroup member density but not the cross-group density moderated the effect of intergroup contact. Separating the effects of these two forms of density was only possible among the 238 respondents with non-white network members in Study 2 because there was hardly any variance in the amount of contact in Study 1 . In Study 2, this moderation was significant at the $p<0.05$ level for the 120 respondents who could name six network contacts and significant at the $p<0.1$ level for the 118 respondents who could name four network contacts. The moderating effect of outgroup member density fits the idea that people might gain more information about their outgroup contacts in a dense network, which in turn reduces the salience of racial group memberships. It is unlikely that subtyping outgroup members as being not representative of their racial group underlies the effect of outgroup member density because this form of density also includes relationships among outgroup members. Cross-group density, which excludes these relationships, did not moderate the effect of intergroup contact.

Despite this supportive evidence, future research is needed that directly tests the proposed mediator for the effect of network density. Reduced membership salience likely is the reason behind the effect of network density but the current study could not establish that individuating information is the underlying cause. There are additional explanations that may reduce group membership salience. A dense network could, for instance, be perceived as more entative or as an important group on its own.

\subsection{Overall network density versus outgroup member density}

Results show that it is important to distinguish between overall density and outgroup member density when investigating the effect of the network structure on intergroup contact. Overall density is based on all relationships that exist in a person's network. It is easy to calculate and thus tempting to use as a measure of the network structure. However, the three proposed mechanisms that could underlie an effect of network density, extended contact, subtyping, and salience of the group membership are all based on relationships that involve the outgroup members of a person's network. Overall density ignores the group membership of network contacts and can thus be strongly influenced by relationships among ingroup members.

This might explain why the interaction between contact and overall density did not yield consistent results across studies. The interaction was significant in Study 1 and in the subsample of respondents who could name six network contacts in Study 2 but not among respondents who could only name four contacts. This could be due to some characteristic of the respondents in this subsample (e.g., they were all not members of a congregation) or due to the smaller size of the networks. But it could also be due to the fact that relationships between ingroup members influenced the indicator of overall network density. In contrast, the interaction between intergroup contact and outgroup member density in Study 2 yielded consistent results in both subsamples. This suggests that future research should not use overall network density as a measure of the network structure in the context of intergroup contact. Instead, the network indicator should be based only on relationships that include outgroup members.

\subsection{Network density and extended contact}

The present findings extend previous research on the relationship between direct and extended contact. Respondents who had direct contact with outgroup members in their network could also have extended contact when ingroup friends were also friends of the outgroup members in a dense social network. Based on the extended contact hypothesis (Vezzali et al., 2014; Wright et al., 1997), one might have expected more positive intergroup attitudes among respondents with a denser cross-group network in which ingroup friends are related to the outgroup friends. However, cross-group density was not related to intergroup attitudes and did also not moderate the effect of direct contact. This suggests that it might not be possible to measure extended contact within small ego-centered networks. Instead, extended contact should involve indirect relationships with outgroup members that are not part of a person's core-network of close friends (Cameron et al., 2011; Tausch et al., 2011). Future research might thus benefit from using a social network approach to differentiate between extended contact that does and does not include direct relationships with outgroup members (Munniksma et al., 2013). 
The finding that outgroup member density moderated the effect of direct contact suggests a new avenue for research on indirect contact. Next to the outgroup friends of one's ingroup friends (extended contact), the outgroup friends of one's outgroup friends might have a unique effect on intergroup attitudes. More research is needed to explore if this effect is restricted to outgroup friends that are part of a person's core network (and are thus personally known) or if this finding generalizes to other indirect outgroup friends.

\subsection{Limitations}

Studying the network structure with ego-centered network data has some limitations that might affect the confidence with which one can draw conclusions. In Study 1, 75.8\% of respondents said that they had a few or more black friends whereas only $22.3 \%$ named at least one black person in their network of people they felt close to. In Study 2 , more than $70 \%$ of the combined sample indicated to talk to non-white people at least once a month whereas only $18.7 \%$ indicated to feel close to at least one non-white person in the ego-centered network. This might suggest that ego-centered network studies considerably underestimate the actual amount of contact a person has. This is reflected in the small amount of explained variance in both studies. The adjusted $R^{2}$ varied only between 0.06 and 0.11 suggesting that contact in such small egocentered networks does not strongly relate to intergroup attitudes. Simply increasing the number of network contacts in an ego-centered network study is probably not the appropriate solution to this problem as the number of relationships that have to be evaluated increase exponentially with the size of the network. ${ }^{9}$ Instead, more research is needed that makes use of different ways to measure social networks (Wölfer et al., 2015) in order to get a better representation of people's social networks.

Both studies suffer from additional limitations due to the study designs. Study 1 made use of a Mechanical Turk sample that is not representative of any population. In the nationally representative sample of Study 2, the separate effects of crossgroup density and outgroup member density could only be tested among the small subsamples of 120 and 118 respondents who named at least one non-white network contact. It might thus be too early to draw firm conclusions about the moderating effect of network density. More research focusing on racially or ethnically more diverse social networks is needed to increase the confidence in the presented findings. Such research should also directly test the proposed mechanisms behind network density, subtyping and salience of the group membership, for which no measures were available.

Future research should also examine the effect of the network structure on intergroup contact based on other characteristics than race. Contact has been found to reduce prejudice toward various different groups such as gays and lesbians, physically or mentally disabled people, and the elderly (Pettigrew \& Tropp, 2006). However, social networks involving people belonging to such groups may have different structures than interracial networks. Social networks tend to be strongly segregated along racial boundaries (McPherson, Smith-Lovin, \& Cook, 2001), which does not only affect the amount of interracial contact people have but also the density of interracial social networks. Future research should test whether the current findings generalize to intergroup contact based on other characteristics than race. Such research should preferably make use of longitudinal data. Even though it seems implausible that prejudiced respondents form denser networks, a cross-sectional analysis, such as in this research, can never rule out the possibility of reversed causality.

\subsection{Conclusion}

The present research seconds recent studies that suggest a new direction for research on intergroup contact (Munniksma et al., 2013; Stark, 2015; Wölfer et al., 2015). The results of this study suggest that the structure of social networks may have important consequences for effects of intergroup contact. Future research may want to extend the focus to other structural characteristics of a social network (Wölfer et al., 2015). For instance, the network position of the outgroup member with whom someone has contact may affect the extent to which this contact affects intergroup attitudes. That is, the notion of centrality (Freeman, 1978) suggests that an outgroup member who is central or well connected in the network may be particularly influential. More research is needed to explore such potential effects of the structure of a network in which intergroup contact takes place on the development of prejudice. Though with clear limitations, the present research gives reason to believe that this might be a fruitful direction for future research.

\section{Funding}

This work was supported by the European Commission [FP7-PEOPLE-2011-IOF, Grant Agreement Number 299939].

\section{Acknowledgements}

I would like to thank Maykel Verkuyten, Andreas Flache, and the participants of the Amsterdam Area Political Psychology Meeting for their helpful comments on earlier versions of this manuscript.

\footnotetext{
9 For instance, in a study with 10 network contacts, respondents would have to elaborate on the existence of 45 potential relationships between these contacts.
} 


\section{Appendix A. Supplementary data}

Supplementary data associated with this article can be found, in the online version, at http://dx.doi.org/10.1016/j.ijintrel.2016.10.004.

\section{References}

Aiken, L. S., \& West, S. G. (1991). Multiple regression: Testing and interpreting interactions. Newbury Park, London: Sage.

Allport, G. W. (1954). The nature of prejudice. Addison-Wesley: Cambridge.

Blair, I. V. (2002). The malleability of automatic stereotypes and prejudice. Personality and Social Psychology Review, 6(3), 242-261.

Bogardus, E. S. (1933). A social-distance scale. Sociology and Social Research, 17, 265-271.

Brown, R., \& Hewstone, M. (2005). An integrative theory of intergroup contact. Advances in Experimental Social Psychology, $37,255-343$.

Burt, R. S. (1984). Network items and the general social survey. Social Networks, 6, 293-339.

Cameron, L., Rutland, A., Hossain, R., \& Petley, R. (2011). When and why does extended contact work? The role of high quality direct contact and group norms in the development of positive ethnic intergroup attitudes amongst children. Group Processes E Intergroup Relations, $14(2), 193-206$.

Christ, O., Schmid, K., Lolliot, S., Swart, H., Stolle, D., Tausch, N., \& Hewstone, M. (2014). Contextual effect of positive intergroup contact on outgroup prejudice. Proceedings of the National Academy of Sciences of the United States of America, 111(11), 3996-4000.

Cialdini, R. B., Kallgren, C. A., \& Reno, R. R. (1991). A focus theory of normative conduct. In M. P. Zanna (Ed.), Advances in experimental social psychology. San Diego, CA: Academic Press.

Davies, K., Tropp, L. R., Aron, A., Pettigrew, T. F., \& Wright, S. C. (2011). Cross-group friendships and intergroup attitudes: A meta-analytic review. Personality and Social Psychology Review, 15(4), 332-351.

Dovidio, J. F., Eller, A., \& Hewstone, M. (2011). Improving intergroup relations through direct, extended and other forms of indirect contact. Group Processes E'Intergroup Relations, 14(2), 147-160.

Emerson, M. O., \& Sikkink, D. (2006). Portraits of american life study, 1st wave.. Retrieved from:. http://www.thearda.com/pals/

Emerson, M. O., Sikkink, D., \& James, A. D. (2010). The panel study on American religion and ethnicity: Background, methods, and selected results. Journal of the Scientific Study of Religion, 49, 162-171.

Falci, C., \& McNeely, C. (2009). Too many friends: Social integration, network cohesion and adolescent depressive symptoms. Social Forces, 87(4), 2031-2061.

Fiske, S. T. (1993). Social cognition and social perception. Annual Review of Psychology, 44(1), 155-194.

Freeman, L. (1978). Centrality in social networks: Conceptual clarification. Social Networks, 1, 215-239.

Haynie, D. L. (2001). Delinquent peers revisited: Does network structure matter? American Journal of Sociology, $106(4), 1013-1057$.

Hewstone, M., \& Brown, R. (1986). Contact is not enough: An intergroup perspective on the 'contact hypothesis'. In M. Hewstone, \& R. Brown (Eds.), Contact and conflict in intergroup encounters (pp. 1-44). Oxford: Blackwell.

Hewstone, M. (1994). Revision and change of stereotypic beliefs: In search of the elusive subtyping model. European Review of Social Psychology, 5, 69-109.

Huijnk, W., Verkuyten, M., \& Coenders, M. (2013). Family relations and the attitude towards ethnic minorities as close kin by marriage. Ethnic and Racial Studies, 39, 1890-1909.

Johnson, B. R., \& Jacobson, C. K. (2005). Contact in context: An examination of social settings on whites' attitudes toward interracial marriage. Social Psychology Quarterly, 68(387), 387-399.

McPherson, M., Smith-Lovin, L., \& Cook, J. M. (2001). Birds of a feather: Homophily in social networks. Annual Review of Sociology, $27,415-444$.

Merino, S. M. (2013). Contact with gays and lesbians and same-sex marriage support: The moderating role of social context. Social Science Research, 42(4), 1156-1166.

Munniksma, A., Stark, T. H., Verkuyten, M., Flache, A., \& Veenstra, D. R. (2013). Extended intergroup friendships within social settings: The moderating role of initial outgroup attitudes. Group Processes E' Intergroup Relations, 16(6), 752-770.

Perry, S. L. (2013). Racial composition of social settings, interracial friendship, and whites' attitudes toward interracial marriage. The Social Science Journal, $50,13-22$.

Pettigrew, T. F., \& Tropp, L. R. (2006). A meta-analytic test of intergroup contact theory. Journal of Personality and Social Psychology, 90(5), 751-783.

Pettigrew, T. F., Christ, O., Wagner, U., \& Stellmacher, J. (2007). Direct and indirect intergroup contact effects on prejudice: A normative interpretation. International Journal of Intercultural Relations, 31(4), 411-425.

Pettigrew, T. F., Tropp, L. R., Wagner, U., \& Christ, O. (2011). Recent advances in intergroup contact theory. International Journal of Intercultural Relations, 35(3), 271-280.

Ryabov, I. (2009). The role of peer social capital in educational assimilation of immigrant youths. Sociological Inquiry, 79(4), 453-480.

Stark, T. H., \& Krosnick, J. A. (2017). GENSI: A new graphical tool to collect ego-centered network data. Social Networks, $48,36-45$.

Stark, T. H. (2015). Understanding the selection bias: Social network processes and the effect of prejudice on the avoidance of outgroup friends. Social Psychology Quarterly, 78(2), 127-150.

StataCorp. (2013). Stata multiple imputation reference manual: Release 13. College Station, TX: StataCorp LP.

Swart, H., Hewstone, M., Christ, O., \& Voci, A. (2011). Affective mediators of intergroup contact: A three-wave longitudinal study in South Africa. Journal of Personality and Social Psychology, 101(6), 1221-1238.

Tausch, N., Hewstone, M., Schmid, K., Hughes, J., \& Cairns, E. (2011). Extended contact effects as a function of closeness of relationship with ingroup contacts. Group Processes E' Intergroup Relations, 14(2), 239-254.

Turner, R. N., Hewstone, M., Voci, A., \& Vonofakou, C. (2008). A test of the extended intergroup contact hypothesis: The mediating role of intergroup anxiety, perceived ingroup and outgroup norms, and inclusion of the outgroup in the self. Journal of Personality and Social Psychology, 95(4), 843-860.

Vezzali, L., Hewstone, M., Capozza, D., Giovannini, D., \& Wölfer, R. (2014). Improving intergroup relations with extended and vicarious forms of indirect contact. European Review of Social Psychology, 25(1), 314-389.

Visintin, E. P., Brylka, A., Green, E. G. T., Mähönen, T. A., \& Jasinskaja-Lahti, I. (2016). The dynamics of interminority extended contact: The role of affective and cognitive mediators. Cultural Diversity and Ethnic Minority Psychology, 1-13, in press

Wölfer, R., Faber, N. S., \& Hewstone, M. (2015). Social network analysis in the science of groups: Cross-Sectional and longitudinal applications for studying intra- and intergroup behavior. Group Dynamics-Theory Research and Practice, 19(1), 45-61.

Wasserman, S., \& Faust, K. (1994). Social network analysis: Methods and applications. Cambridge: University Press.

Weber, R., \& Crocker, J. (1983). Cognitive processes in the revision of stereotypic beliefs. Journal of Personality and Social Psychology, $45(5), 961-977$.

Wright, S. C., Aron, A., McLaughlin-Volpe, T., \& Ropp, S. A. (1997). The extended contact effect: Knowledge of cross-Group friendships and prejudice. Journal of Personality and Social Psychology, 73(1), 73-90. 